\title{
Seed and Embryo Germination in Ardisia crenata
}

\author{
Takahiro Tezuka, Hisa Yokoyama, Hideyuki Tanaka, Shuji Shiozaki, and Masayuki Oda
}

Graduate School of Life and Environmental Sciences, Osaka Prefecture University, 1-1 Gakuen-cho, Nakaku, Sakai, Osaka 599-8531, Japan

Correspondence should be addressed to Masayuki Oda, moda@plant.osakafu-u.ac.jp

Received 27 September 2012; Revised 8 November 2012; Accepted 9 November 2012

Academic Editor: Philip J. White

Copyright ( $\odot 2012$ Takahiro Tezuka et al. This is an open access article distributed under the Creative Commons Attribution License, which permits unrestricted use, distribution, and reproduction in any medium, provided the original work is properly cited.

\begin{abstract}
Ardisia crenata is an evergreen shrub with attractive bright red berries. Although this species is usually propagated by seed, the seeds take a long time to germinate with conventional sowing methods. We investigated the germination capacity of seeds and embryos collected in different months and the effects of seed storage conditions, germination temperature, water permeability of the seed coat, and the endosperm on seed germination. Seeds and embryos collected in late September or later showed good germination rates. Seeds germinated more rapidly after longer periods of storage at low temperature (approximately $5^{\circ} \mathrm{C}$ ), and those stored in dry conditions showed lower emergence frequency than those stored in wet conditions. Seeds germinated at 15$30^{\circ} \mathrm{C}$, but not at $5-10^{\circ} \mathrm{C}$. Removal of the seed coat enhanced water uptake and seed germination. Seeds with various proportions of the removed seed coat were sown on a medium supplemented with sucrose. The germination frequency increased as the size of the remaining endosperm decreased. However, the opposite results were obtained when seeds were sown on a medium without sucrose. We concluded that the optimal temperature of $25^{\circ} \mathrm{C}$ is the most critical factor for seed germination in A. crenata.
\end{abstract}

\section{Introduction}

The genus Ardisia (Myrsinaceae) contains approximately 400-500 species of evergreen shrubs, which are distributed in the subtropical and tropical regions around the world [1]. Several Ardisia species have been used for medicinal purposes, because they contain a wide array of biologically active phytochemical constituents such as bergenin and ardisin [2].

Ardisia crenata is one of the most widely grown species in the genus and is distributed throughout East Asia, including Japan. It grows to approximately $1 \mathrm{~m}$ high and has glossy, dark green leaves, and attractive bright red berries. It is grown as an ornamental plant in gardens and as a houseplant. Although vegetative propagation methods such as cuttings are sometimes used to propagate $A$. crenata plants [3], the use of seeds has advantages for mass propagation. However, it can take more than 13 weeks to achieve $80 \%$ of seed germination [3]. This long period for seed germination hinders and delays the breeding of this shrub.
Seed germination is controlled by several environmental factors, such as seed moisture content, temperature, and light. Seed condition also affects germination; for example, the seed coat may be water impermeable, or the mature seed may contain an underdeveloped embryo that only grows to full size after imbibition $[4,5]$. In Japan, fully ripened fruits of $A$. crenata are usually harvested in winter. The seeds are washed with water to remove the fruit pulp and are then buried in wet sand for storage under natural low-temperature conditions. These seeds are sown in the following spring and germinate in early summer. Although this is the traditional method of cultivation, the seeds require a long germination period and show considerable variations in the timing of germination. Furthermore, it is unclear whether high-soil moisture and low temperature during seed storage are essential for seed germination and what temperature is optimal for seed germination.

In the present study, we investigated the germination capacity of seeds and embryos collected in different months. We investigated seed responses to low temperature and soil 
moisture levels during seed storage. In addition, the effects of germination temperature, water permeability of the seed coat, and the effects of the seed coat and endosperm on germination were investigated.

\section{Materials and Methods}

2.1. Plant Materials. Fruits were harvested from A. crenata plants cultivated in a field at Osaka Prefecture University. Seeds were washed with water to remove the fruit pulp and used in the experiments.

2.2. Germination or Emergence Test of Seeds and Embryos. Seeds collected on 18 January 2005 were sown according to the conventional method as follows. Seeds were buried in vermiculite-filled plastic boxes $(6 \mathrm{~cm} \times 6 \mathrm{~cm} \times 9 \mathrm{~cm}$ height $)$ and were stored outdoors under ambient low-temperature conditions at approximately $5^{\circ} \mathrm{C}$ with protection from the wind and rain. The vermiculite was constantly moistened by spraying with water. The seeds were sown in a 288-cell tray $(10 \mathrm{~mL} / \mathrm{cell})$ filled with wet vermiculite at 12 weeks after the initiation of seed storage (13 April). The seeds were placed outdoors, and observations of seedling emergence were recorded for 126 days after sowing (DAS).

Embryo culture was carried out as follows. Seeds collected on 9 January 2007 were sterilized with $70 \%$ ethanol for $30 \mathrm{~s}$ and then with 5\% sodium hypochlorite for $15 \mathrm{~min}$. Embryos were excised from the sterilized seeds, placed in flat-bottomed test tubes ( $25 \mathrm{~mm}$ diameter, $100 \mathrm{~mm}$ length) containing MS medium [6] supplemented with $3 \%$ sucrose and $0.85 \%$ agar ( $\mathrm{pH} 5.8$ ), and then incubated at $25^{\circ} \mathrm{C}$ in the dark. Observations of embryo germination were recorded for 126 days after the initiation of incubation (DAI).

Seeds collected at monthly intervals (23 August, 27 September, 25 October, and 22 November, 2007) were used to investigate whether seed and embryo germination capacity was related to seed developmental stage. Some nonsterilized seeds were sown in Petri dishes containing wet filter paper and then incubated at $25^{\circ} \mathrm{C}$ in the dark. Other seeds were used for embryo culture. For seeds collected on 27 September, 25 October, and 22 November, the embryos were removed and cultured in vitro as described above. It was impossible to isolate embryos from seeds collected on 23 August because the embryos were immature and too small to excise. Therefore, the seeds harvested on 23 August were aseptically sown in flat-bottomed test tubes containing MS medium supplemented with $3 \%$ sucrose and $0.85 \%$ agar $(\mathrm{pH}$ 5.8) and then cultured at $25^{\circ} \mathrm{C}$ in the dark. Observations of germination of embryos and seeds were recorded for 126 DAS or DAI.

2.3. Effects of Seed Storage Conditions. To determine whether A. crenata seeds show seed dormancy, which is broken by low temperature, we investigated the ability of seeds stored at low temperature (approximately $5^{\circ} \mathrm{C}$ ) for different periods to germinate. Seeds collected on 18 January 2005 were buried in vermiculite-filled plastic boxes and were stored outdoors under ambient low-temperature conditions with protection from the wind and rain. The vermiculite was constantly moistened by spraying with water. The seeds were transferred to an incubator at $20^{\circ} \mathrm{C}$ at 4 -week intervals (18 January, 15 February, and 15 March). The seeds were temporarily removed from the plastic boxes every 7 days and their germination evaluated. Observations were recorded for 84 days after the initiation of storage.

Seed dormancy is also related to seed moisture content. Therefore, we evaluated seedling emergence from seeds stored under wet or dry conditions. Seeds collected on 18 January 2005 were buried in vermiculite-filled plastic boxes and stored outdoors under ambient low-temperature conditions with protection from the wind and rain. The vermiculite was constantly moistened by spraying with water (wet conditions) or was not moistened (dry conditions). The seeds were sown in a 288-cell tray filled with wet vermiculite at 12 weeks after the initiation of seed storage (13 April) and placed outdoors. Observations of seed emergence were recorded for 126 DAS.

2.4. Effects of Temperature on Germination. To determine the optimal temperature for seed germination, seeds were sown in plastic boxes filled with wet vermiculite immediately after harvest on 18 January 2005 and incubated at 5, 10, 15, 20, 25 , or $30^{\circ} \mathrm{C}$ in the dark. The seeds were temporarily removed from the plastic boxes every 7 days and their germination evaluated. Observations were recorded for 84 DAS.

2.5. Effects of Scarification and Seed Coat Removal. The effect of the seed coat on seed germination was investigated. Seeds were collected on 13 June 2006. The seed coats of some seeds were scarified or completely removed. The seeds (intact seeds, scarified seeds, and seeds without the seed coat) were sown in Petri dishes containing wet filter paper and incubated at $25^{\circ} \mathrm{C}$ in the dark. Observations of seed germination were recorded for 22 DAS.

Methylene blue has been used to determine the water permeability of seeds [7]. To examine the water permeability of the seed coat, intact seeds and seeds without seed coats were prepared using seeds collected on 25 October 2007. These seeds were immersed in $1 \%$ methylene blue for $24 \mathrm{~h}$, washed with water, cut, and observed under a stereomicroscope (Olympus SZ60, Tokyo, Japan).

2.6. Effects of Endosperm Removal. Isolated embryos germinated immediately, whereas seeds took several weeks to germinate (see below; Table 1). Therefore, it was hypothesized that inhibitors present in the endosperm interfered with seed germination. To test this hypothesis, the seed coat and some or all of the endosperm were removed from embryos (Figure 1), and the growth of the seeds/embryos on MS medium with or without sucrose was evaluated. Seeds were collected on 23 November 2006 and sterilized with $70 \%$ ethanol for $30 \mathrm{~s}$ and then with $5 \%$ sodium hypochlorite for $15 \mathrm{~min}$. Five types of seeds were prepared: intact seeds (Figure 1(a)), seeds without seed coat (Figure 1(b)), seeds without seed coat and micropylar endosperm (Figure 1(c)), seeds without seed coat and half 
TABLE 1: Seedling emergence and germination of isolated A. crenata embryos.

\begin{tabular}{|c|c|c|c|c|}
\hline \multirow{2}{*}{ Method } & Number of & seeds or embryos & \multirow{2}{*}{ Emergence or germination (\%) } & \multirow{2}{*}{ Number of days to emergence or germination ${ }^{\mathrm{a}}$} \\
\hline & Sown or cultured & Emerged or germinated & & \\
\hline Seed sowing & 30 & 27 & 90 & $71.8 \pm 2.4$ \\
\hline Embryo culture & 10 & 10 & 100 & $11.9 \pm 1.1$ \\
\hline
\end{tabular}

Observations were continued for 126 days after sowing or incubation.

${ }^{\text {a }}$ Data are expressed as mean $\pm \mathrm{SE}$.

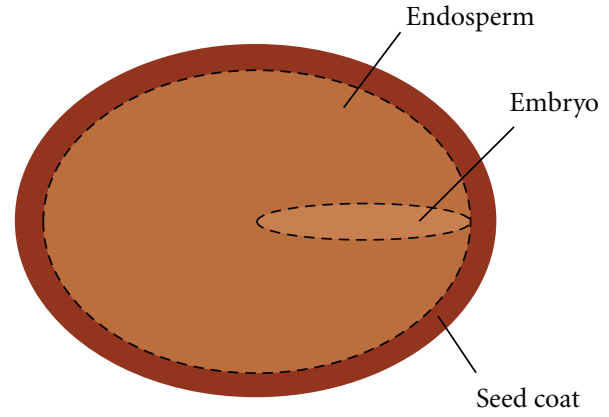

(a)

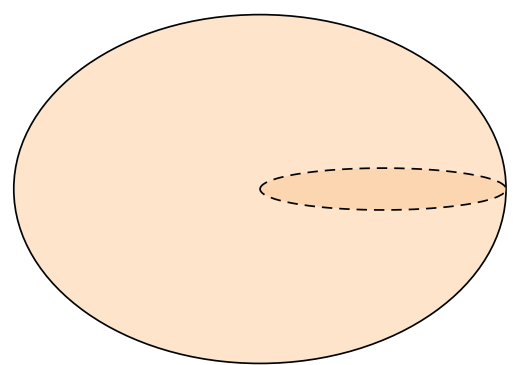

(b)

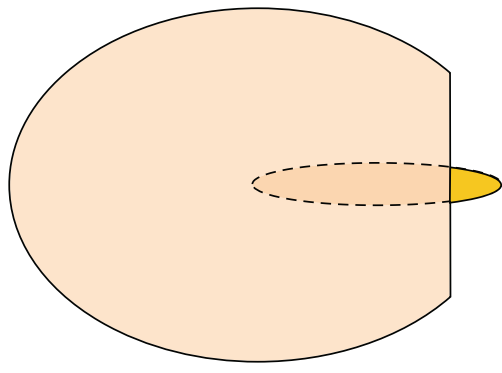

(c)

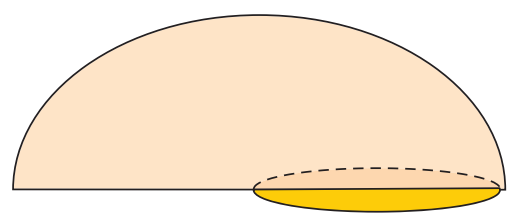

(d)

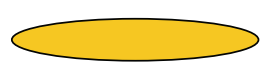

(e)

Figure 1: Schematic illustration of A. crenata seeds with seed coat and some or all of the endosperm removed. These seeds were used to investigate the effects of the endosperm/seed coat on seed germination. (a) Intact seed with seed coat; (b) seed without seed coat; (c) seed without seed coat and micropylar endosperm; (d) seed without seed coat and half of the endosperm; (e) seed without seed coat and endosperm (isolated embryo).

of the endosperm (Figure 1(d)), and seeds without both seed coat and endosperm (only embryos; Figure 1(e)). Four types of these seeds (excluding seeds without the seed coat) were placed in flat-bottomed test tubes that contained MS medium supplemented with $3 \%$ sucrose and $0.85 \%$ agar $(\mathrm{pH}$ 5.8) and then cultured at $25^{\circ} \mathrm{C}$ in the dark. Observations of seed germination were recorded for 42 DAI.

Seeds collected on 28 December 2006 were also treated as mentioned above. To examine the effects of sucrose on germination, five types of seeds listed above were placed in flat-bottomed test tubes that contained MS medium supplemented with $0.85 \%$ agar $(\mathrm{pH}$ 5.8) and then cultured at $25^{\circ} \mathrm{C}$ in the dark. Observations of seed germination were recorded for 42 DAI.

\section{Results}

3.1. Germination or Emergence Test of Seeds and Embryos. Out of 30 seeds sown using the conventional method, 27 seedlings emerged at $71.8 \pm 2.4$ DAS. Embryos cultured at $25^{\circ} \mathrm{C}$ germinated earlier; all 10 embryos germinated at $11.9 \pm$ 1.1 DAI (Table 1).

To determine the effects of harvest time on embryo and seed germination, seeds and embryos collected at monthly intervals (23 August, 27 September, 25 October, and 22 November) were sown or cultured at $25^{\circ} \mathrm{C}$ (Table 2). The length of immature embryos in seeds collected on 23 August could not be determined, but seeds collected on 27 September contained embryos $2.37 \pm 0.05 \mathrm{~mm}$ long. The length of the embryos did not increase significantly in seeds collected on 25 October and 22 November. When seeds were sown in vivo, those collected on 23 August did not germinate. However, seeds collected in the other three months germinated. On the other hand, $20 \%$ of the seeds collected on 23 August germinated when sown in vitro. All embryos in seeds collected on 27 September or later germinated.

3.2. Effects of Seed Storage Conditions. There was no change in embryo length during low-temperature storage (approximately $5^{\circ} \mathrm{C}$ ) (data not shown). Germination was not 
TABLe 2: Germination of A. crenata seeds and embryos collected in different months in 2007.

\begin{tabular}{lccc}
\hline Date of seed collection & Length of embryo $(\mathrm{mm})^{\mathrm{a}}$ & \multicolumn{2}{c}{ Germination $(\%)^{\text {Embryo }^{\mathrm{b}}}$} \\
\hline 23 August & - & 0 & $20^{\mathrm{c}}$ \\
27 September & $2.37 \pm 0.05$ & 100 & 100 \\
25 October & $2.27 \pm 0.06$ & 100 & 100 \\
22 November & $2.32 \pm 0.06$ & 100 & 100 \\
\hline
\end{tabular}

Observations were continued for 126 days after sowing or incubation.

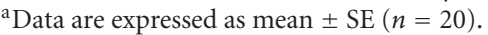

${ }^{\mathrm{b}} n=20$.

${ }^{\mathrm{c}}$ Intact seeds harvested on 23 August were sown in vitro because the embryos were immature.

TABLE 3: Germination of A. crenata seeds stored at low temperature.

\begin{tabular}{|c|c|c|c|c|c|}
\hline \multicolumn{2}{|c|}{ Number of days } & \multicolumn{2}{|c|}{ Number of seeds } & \multirow{2}{*}{ Germination (\%) } & \multirow{2}{*}{ Number of days to germination after transfer to $20^{\circ} \mathrm{C}^{a}$} \\
\hline $5^{\circ} \mathrm{C}$ & $20^{\circ} \mathrm{C}$ & Sown & Germinated & & \\
\hline 0 & 84 & 50 & 50 & 100 & $40.6 \pm 0.7 \mathrm{a}$ \\
\hline 28 & 56 & 50 & 50 & 100 & $31.5 \pm 1.4 \mathrm{~b}$ \\
\hline 56 & 28 & 50 & 48 & 96 & $23.1 \pm 0.7 \mathrm{c}$ \\
\hline 84 & 0 & 50 & 0 & 0 & - \\
\hline
\end{tabular}

Observations were continued for 84 days after storage.

${ }^{a}$ Data are expressed as mean \pm SE. Means followed by a different letter are significantly different $(P<0.05$, Tukey's multiple comparison test).

observed in seeds stored at $5^{\circ} \mathrm{C}$ for 84 days (Table 3 ). Conversely, most seeds transferred from $5^{\circ} \mathrm{C}$ to $20^{\circ} \mathrm{C}$ germinated. The number of days to germination was significantly different depending on the timing of transfer to $20^{\circ} \mathrm{C}$. Seeds stored at $5^{\circ} \mathrm{C}$ for 0,28 , and 56 days after storage required $40.6 \pm 0.7,31.5 \pm 1.4$, and $23.1 \pm 0.7$ days to germinate, respectively.

Seeds stored under wet conditions showed 90\% emergence at $71.8 \pm 2.4$ DAS (Table 4). Those stored under dry conditions showed $73 \%$ emergence after a longer germination period $(81.1 \pm 2.2 \mathrm{DAS})$.

3.3. Effects of Temperature on Germination. All seeds germinated at $20^{\circ} \mathrm{C}-30^{\circ} \mathrm{C}$ and $58 \%$ of seeds germinated at $15^{\circ} \mathrm{C}$. No seeds germinated at $5^{\circ} \mathrm{C}-10^{\circ} \mathrm{C}$ (Table 5). The most rapid seed germination was at $25^{\circ} \mathrm{C}(30.1 \pm 0.7 \mathrm{DAS})$. The number of days to germinate at 30,20 , and $15^{\circ} \mathrm{C}$ was $32.2 \pm 0.7$, $40.6 \pm 0.7$, and $77.0 \pm 1.4$, respectively.

3.4. Effects of Scarification and Seed Coat Removal. Germination of seeds lacking the seed coat was observed from 7 DAS at $25^{\circ} \mathrm{C}$, and the germination frequency reached $100 \%$ at 18 DAS (Figure 2(a)). In contrast, germination was delayed in intact seeds (with the seed coat) and scarified seeds. These seeds started to germinate at 10 DAS, and the germination frequency of intact and scarified seeds reached $100 \%$ at 20 and 21 DAS, respectively (Figure 2(a)).

Intact seeds and seeds without the seed coat were immersed in methylene blue, and the water permeability of the seeds was investigated. In intact seeds, only the seed coat was stained, which indicated that the seed coat prevented imbibition (Figure 2(b)). Conversely, the endosperm was stained in seeds without the seed coat (Figure 2(c)).

3.5. Effects of Endosperm Removal. Among the four types of seeds (Figure 1) cultured on MS medium supplemented with sucrose, isolated embryos showed the highest and 100\% of embryos had germinated at 14 DAI (Figure 3(a)). Seeds without the seed coat and with half of the endosperm showed the next highest germination frequency, followed by seeds without the seed coat and micropylar endosperm. No germination was observed in intact seeds during 42 DAI.

When five types of seeds (Figure 1) were cultured on MS medium without sucrose, isolated embryos and seeds without the seed coat and half of the endosperm did not germinate, whereas the other three types of seeds germinated (Figure 3(b)). On MS medium without sucrose, seeds lacking the seed coat showed the best germinability (100\% germination by $35 \mathrm{DAI})$.

\section{Discussion}

Although A. crenata seeds germinated with the conventional method, they required a long period for seed germination (Table 1). To facilitate the seedling propagation and to accelerate the generation turnover in breeding programs, development of a rapid seed germination method is desirable. For these purposes, embryo culture was the most suitable method (Table 1). Alternatively, the time required for seed germination could be reduced by optimizing storage conditions and germination temperature, and by removing the seed coat. 
TABLE 4: Emergence of A. crenata seeds stored under wet or dry conditions.

\begin{tabular}{lcccc}
\hline \multirow{2}{*}{ Storage condition } & \multicolumn{2}{c}{$\begin{array}{c}\text { Number of seeds } \\
\text { Emerged }\end{array}$} & Emergence (\%) & Number of days to emergence $^{\mathrm{a}}$ \\
\hline Wet & 30 & 27 & 90 & $71.8 \pm 2.4 \mathrm{a}$ \\
Dry & 30 & 22 & 73 & $81.1 \pm 2.2 \mathrm{~b}$ \\
\hline
\end{tabular}

Observations were continued for 126 days after sowing.

${ }^{a}$ Data are expressed as mean \pm SE. Means followed by a different letter are significantly different $(P<0.05$, Tukey's test $)$.

TABLE 5: Germination of A. crenata seeds at different temperatures.

\begin{tabular}{lcccc}
\hline Temperature $\left({ }^{\circ} \mathrm{C}\right)$ & Sown & $\begin{array}{c}\text { Number of seeds } \\
\text { Germinated }\end{array}$ & Germination $(\%)^{\text {Number of days to germination }}{ }^{\mathrm{a}}$ \\
\hline 5 & 50 & 0 & 0 & - \\
10 & 50 & 0 & 0 & - \\
15 & 50 & 29 & 58 & $47.0 \pm 1.4 \mathrm{a}$ \\
20 & 50 & 50 & 100 & $30.6 \pm 0.7 \mathrm{~b}$ \\
25 & 50 & 50 & 100 & $30.1 \pm 0.7 \mathrm{c}$ \\
30 & 50 & 50 & 100 & $32.2 \pm 0.7 \mathrm{c}$ \\
\hline
\end{tabular}

Observations were continued for 84 days after sowing.

${ }^{a}$ Data are expressed as mean \pm SE. Means followed by a different letter are significantly different $(P<0.05$, Tukey's multiple comparison test $)$.

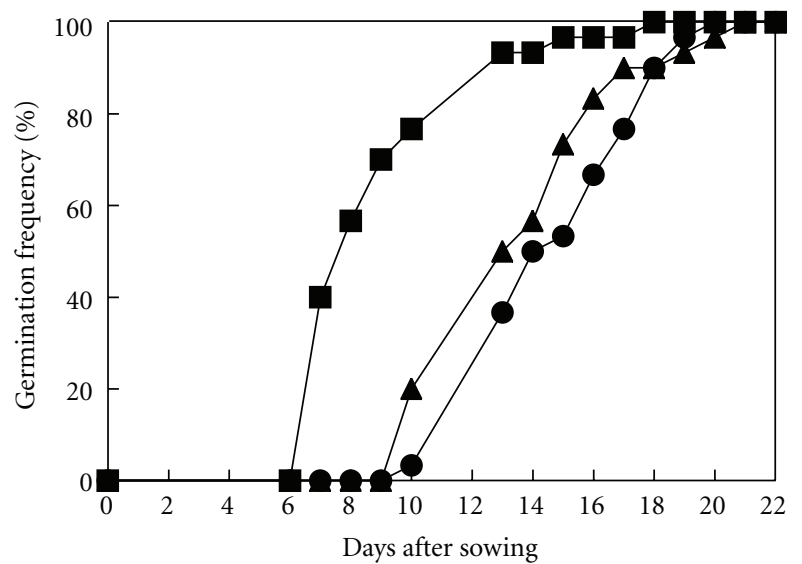

(a)

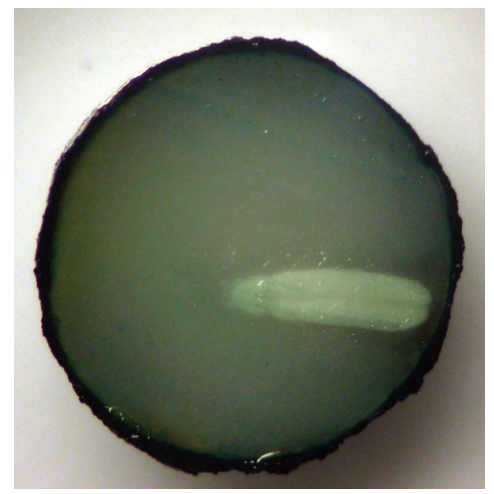

(b)

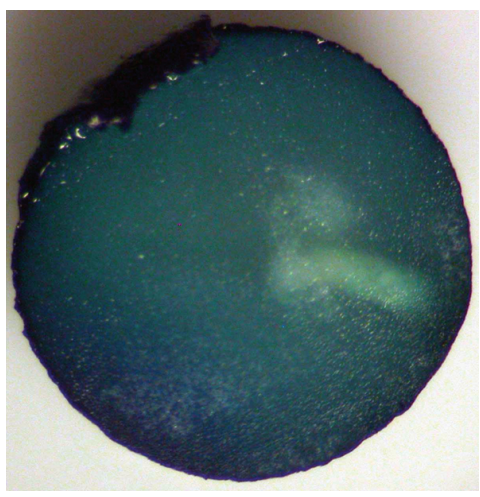

(c)

FIgURE 2: Effects of scarification and seed coat removal on seed germination in A. crenata. (a) Germination frequency of intact seeds (circles), scarified seeds (triangles), and seeds without the seed coat (squares). (b) and (c) Water permeability of seeds. Intact seeds (b) and seeds without the seed coat (c) were immersed in $1 \%$ methylene blue, and cut surfaces were photographed. 


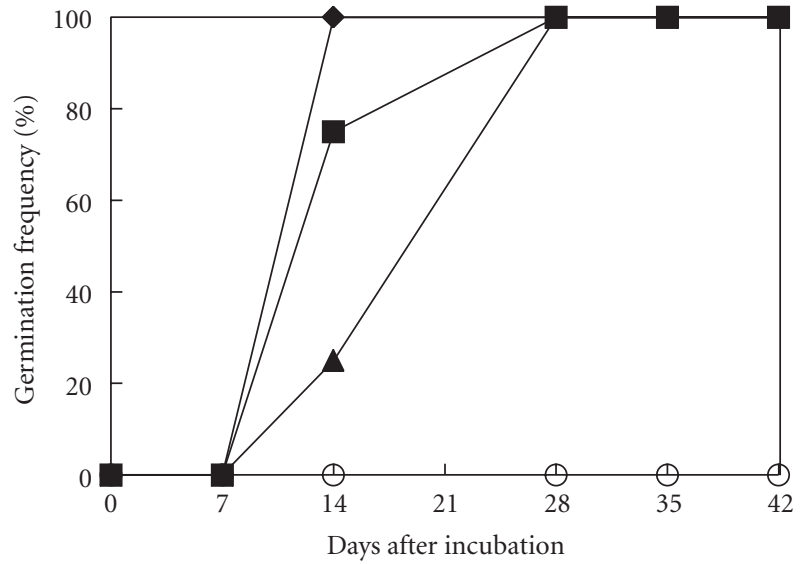

(a)

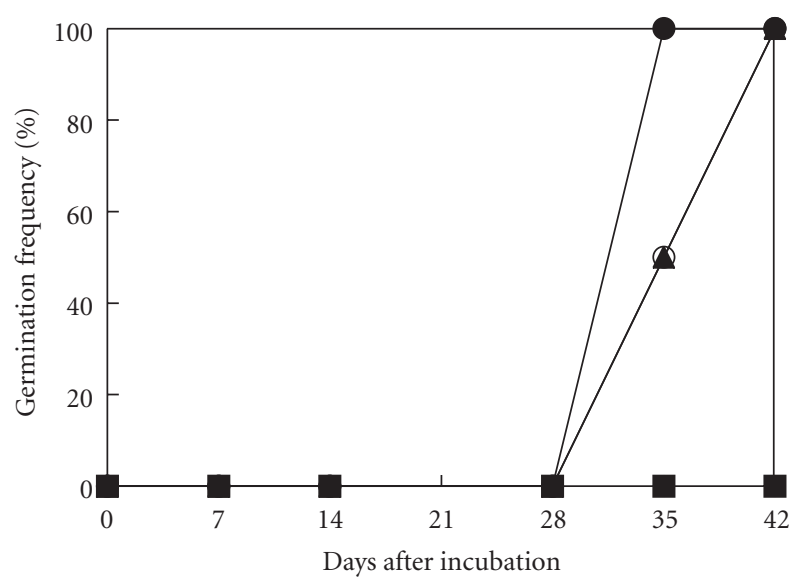

(b)

FIGURE 3: Germination frequencies of A. crenata seeds with seed coat and some or all of the endosperm removed (see Figure 1). Seeds were cultured on MS medium supplemented with sucrose (a) or without sucrose (b). Open circle: intact seeds with seed coat; filled circle: seeds without seed coat; triangles: seeds without seed coat and micropylar endosperm; squares: seeds without seed coat and half of the endosperm; diamonds: seeds without seed coat and endosperm (isolated embryos). Note that open circles and triangles, and squares and diamonds overlapped in (b).

In Japan, A. crenata usually flowers in July and subsequently produces berries. Seeds harvested in late August contained immature embryos. Consequently the germination frequencies of these seeds sown in vivo and embryos cultured in vitro at $25^{\circ} \mathrm{C}$ were $0 \%$ and $20 \%$, respectively (Table 2). By late September, embryos were more developed and $100 \%$ of the embryos and seeds germinated. A decrease in the germinability or induction of further dormancy in seeds harvested in late October or later was not observed. Therefore, seeds of A. crenata were considered to reach maximum germinability during September.

Seeds of A. crenata germinated at $20^{\circ} \mathrm{C}$, regardless of storage at low temperature. However, the seeds germinated more rapidly after longer periods of storage at low temperature (Table 3). Because there was no change in embryo length during storage, it is likely that the earlier germination was related to breaking of dormancy, rather than the stage of embryo development.

Seeds stored in dry conditions showed lower germination frequency and slower emergence than those stored in wet conditions (Table 4). Yang et al. [8] also reported that seeds stored under dry conditions for 90 days did not germinate in A. crenata var. bicolor. Moisture conditions during seed storage often influence seed germination. Partial drying of dormant seeds of Zizania palustris increased the germination response [9]. Conversely, in Cucumis sativus var. hardwickii, seed germination was improved by storing seeds at higher humidity [10]. Drying of seeds induced seed dormancy (secondary dormancy) in Sorghum vulgare [11] and Panicum virgatum [12]. Further research is required to determine whether secondary dormancy is induced if seed viability is lost during dry storage of A. crenata seeds.

Among the germination temperatures tested, A. crenata seeds germinated at $15-30^{\circ} \mathrm{C}$ but not at $5^{\circ} \mathrm{C}-10^{\circ} \mathrm{C}$ (Table 5).
In the traditional method of seed germination in Japan, $A$. crenata seeds are sown in spring and germinate in early summer. This long period required for seed germination is because the suitable temperature for seed germination is relatively high $\left(20^{\circ} \mathrm{C}-30^{\circ} \mathrm{C}\right)$.

Seed coat removal enhanced seed germination in A. crenata (Figure 2(a)). A water permeability test with methylene blue solution showed that seed coat removal enhanced water uptake by seeds (Figures 2(b) and 2(c)). Stabell et al. [13] reported that the seed coat regulates dormancy partly by restricting diffusion of $\mathrm{O}_{2}$ to the embryo in Cynoglossum officinale. Therefore, the seed coat in A. crenata might inhibit water uptake as well as $\mathrm{O}_{2}$ uptake during seed germination.

In A. crenata, isolated embryos germinated more rapidly than seeds (Table 1). Therefore, we considered that certain inhibitors such as abscisic acid (ABA) contained in the endosperm might interfere with seed germination. In Arabidopsis, ABA synthesized in the endosperm induces seed dormancy $[14,15]$. In the present study, when several types of $A$. crenata seeds were sown in medium containing sucrose, the germination frequency increased with a decreasing size of the remaining endosperm (Figure 3(a)). However, in sucrose-free medium, isolated embryos, and seeds without the seed coat and half of the endosperm did not germinate, whereas seeds retaining a greater proportion of the endosperm germinated (Figure 3(b)). Carbohydrates such as sucrose play an important role in physiological processes in plants. During seed germination, carbohydrate reserves serve as an energy source [16]. With this point in mind, it was hypothesized that sucrose in the medium was more suitable as an energy source for germination than reserve materials in the endosperm in A. crenata. Therefore, the promotion of the germination by endosperm removal may be because of absorption of sucrose, which is readily available as an 
energy source, and not the result of the removal of inhibitors contained in the endosperm.

In conclusion, the optimal temperature of $25^{\circ} \mathrm{C}$ was the most critical factor for seed germination in A. crenata. For accelerated emergence of $A$. crenata seedlings, the seeds should be harvested in late September and immediately sown at $25^{\circ} \mathrm{C}$. Seed germination is further enhanced by removing the seed coat. If seeds must be stored before sowing, they should be stored at a low temperature (approximately $5^{\circ} \mathrm{C}$ ) under moist conditions.

\section{References}

[1] C. Chen and J. J. Pipoly, "Myrsinaceae," in Flora of China, Z. Wu and P. H. Raven, Eds., vol. 15, pp. 1-38, Missouri Botanical Garden Press, St. Louis, Mo, USA, 1996.

[2] H. Kobayashi and E. de Mejía, "The genus Ardisia: a novel source of health-promoting compounds and phytopharmaceuticals," Journal of Ethnopharmacology, vol. 96, no. 3, pp. 347-354, 2005.

[3] M. S. Roh, A. K. Lee, and J. K. Suh, "Production of high quality Ardisia plants by stem tip cuttings," Scientia Horticulturae, vol. 104, no. 3, pp. 293-303, 2005.

[4] R. L. Geneve, "Impact of temperature on seed dormancy," HortScience, vol. 38, no. 3, pp. 336-341, 2003.

[5] J. M. Baskin and C. C. Baskin, "A classification system for seed dormancy," Seed Science Research, vol. 14, no. 1, pp. 116, 2004.

[6] T. Murashige and F. Skoog, "A revised medium for rapid growth and bio assays with tobacco tissue cultures," Physiologia Plantarum, vol. 15, pp. 473-497, 1962.

[7] A. Orozco-Segovia, J. Márquez-Guzmán, M. E. SánchezCoronado, A. Gamboa de Buen, J. M. Baskin, and C. C. Baskin, "Seed anatomy and water uptake in relation to seed dormancy in Opuntia tomentosa (Cactaceae, Opuntioideae)," Annals of Botany, vol. 99, no. 4, pp. 581-592, 2007.

[8] Q. H. Yang, W. H. Ye, Z. M. Wang, and X. J. Yin, "Seed germination physiology of Ardisia crenata var. bicolor," Seed Science and Technology, vol. 37, no. 2, pp. 291-302, 2009.

[9] C. D. Aldridge and R. J. Probert, "Effects of partial drying on seed germination in the aquatic grasses Zizania palustris L. and Porteresia coarctata (Roxb.) Tateoka," Seed Science Research, vol. 2, pp. 199-205, 1992.

[10] L. A. Weston, R. L. Geneve, and J. E. Staub, "Seed dormancy in Cucumis sativus var. hardwickii (Royle) Alef.," Scientia Horticulturae, vol. 50, no. 1-2, pp. 35-46, 1992.

[11] G. E. Nutile and L. W. Woodstock, "The influence of dormancy-inducing desiccation treatments on the respiration and germination of sorghum," Physiologia Plantarum, vol. 20, pp. 554-561, 1967.

[12] Z. X. Shen, D. J. Parrish, D. D. Wolf, and G. E. Welbaum, "Stratification in switchgrass seeds is reversed and hastened by drying," Crop Science, vol. 41, no. 5, pp. 1546-1551, 2001.

[13] E. Stabell, M. K. Upadhyaya, and B. E. Ellis, "Role of seed coat in regulation of seed dormancy in houndstongue (Cynoglossum officinale)," Weed Science, vol. 46, no. 3, pp. 344350, 1998.

[14] V. Lefebvre, H. North, A. Frey et al., "Functional analysis of Arabidopsis NCED6 and NCED9 genes indicates that ABA synthesized in the endosperm is involved in the induction of seed dormancy," The Plant Journal, vol. 45, no. 3, pp. 309-319, 2006.
[15] K. P. Lee, U. Piskurewicz, V. Turečková, M. Strnad, and L. Lopez-Molina, "A seed coat bedding assay shows that RGL2dependent release of abscisic acid by the endosperm controls embryo growth in Arabidopsis dormant seeds," Proceedings of the National Academy of Sciences of the United States of America, vol. 107, no. 44, pp. 19108-19113, 2010.

[16] T. R. Johnson, M. E. Kane, and H. E. Pérez, "Examining the interaction of light, nutrients and carbohydrates on seed germination and early seedling development of Bletia purpurea (Orchidaceae)," Plant Growth Regulation, vol. 63, no. 1, pp. 89-99, 2011. 

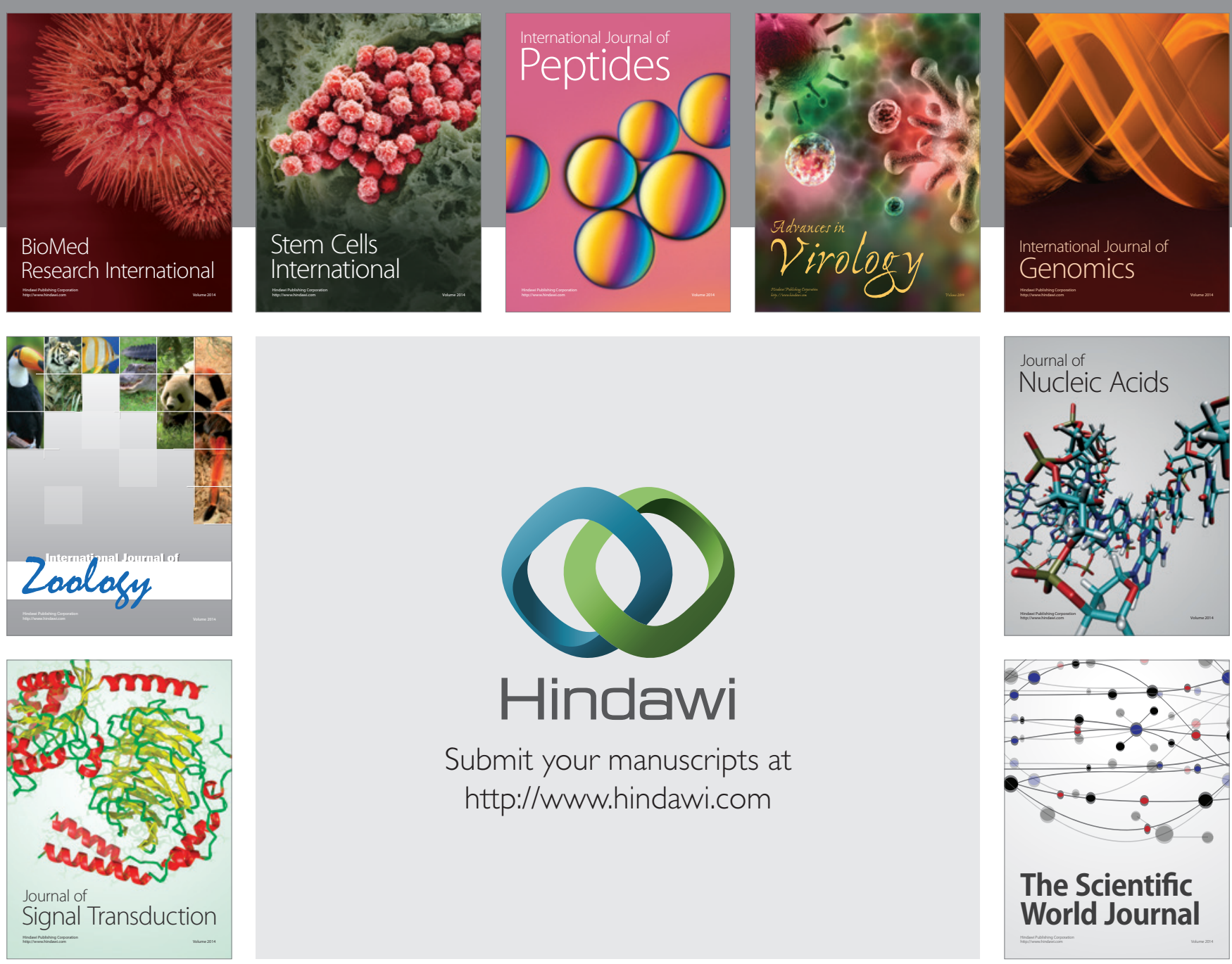

Submit your manuscripts at

http://www.hindawi.com
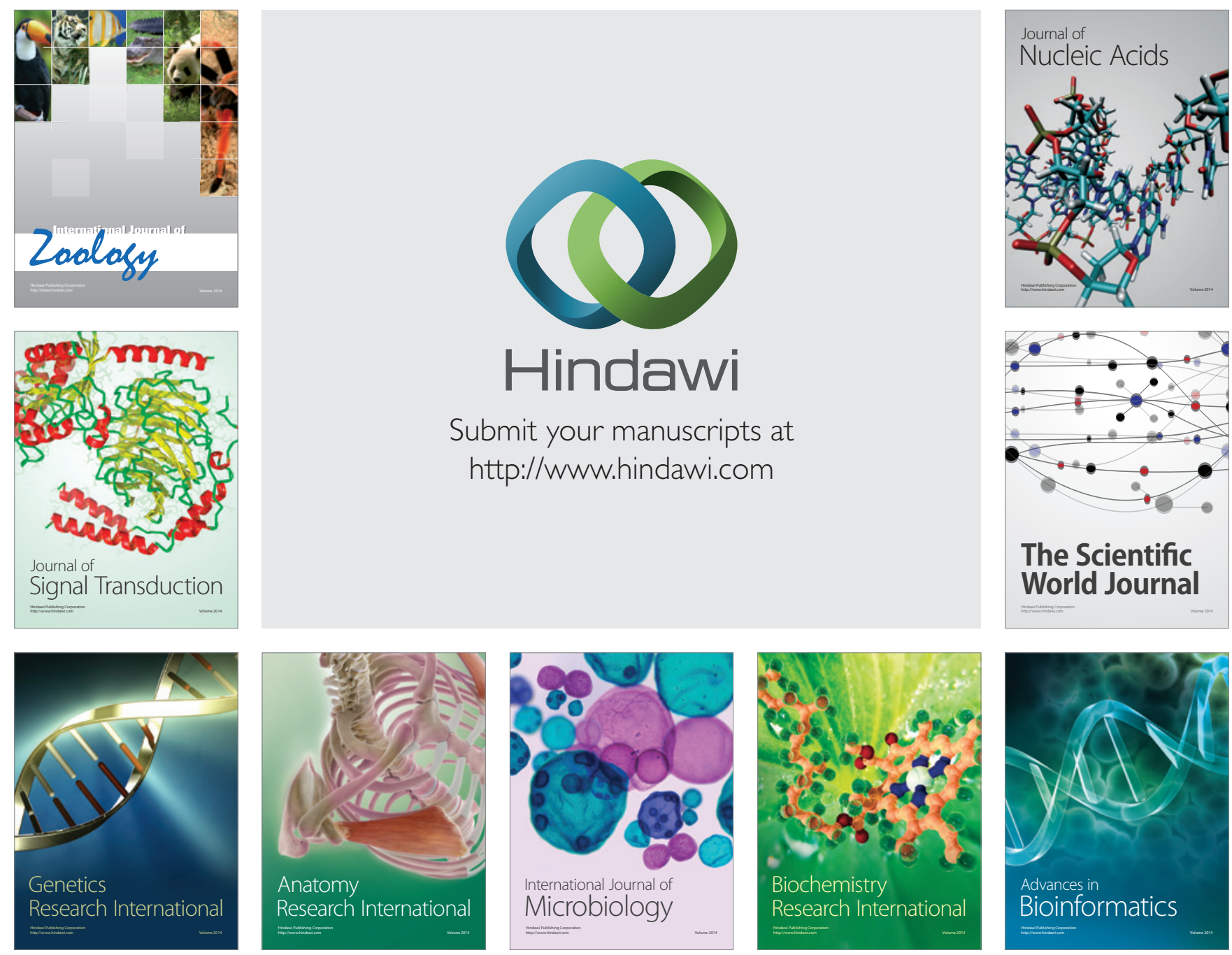

The Scientific World Journal
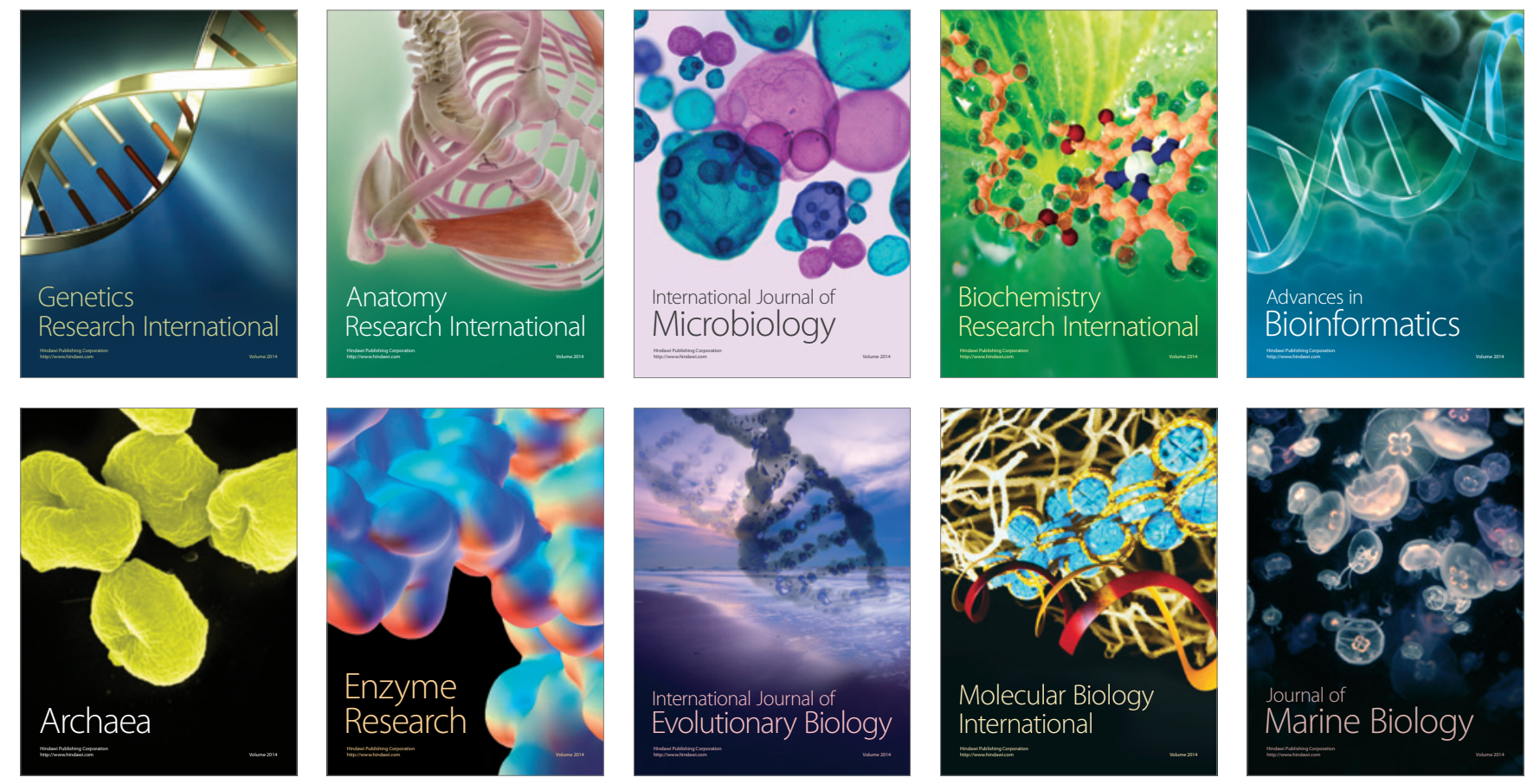